finger (24\%). The most frequent user group was machinery (15\%), followed by chemical agents (14\%). 35 thousand victims were nursing technicians (6\%). 18.8 thousand occurred in adolescents. Men were $60 \%$ and in the age group 18-24 years were 672 thousand. In women, the most frequent age group was 30-34 years.

Conclusion Analyzing periodic data and from different sources can contribute to a profile of work accidents with the implementation of public policies in Brazil.

\section{P-134 COVID-19: ANALYSIS OF NOTIFICATIONS ACCORDING TO SOCIAL SECURITY BENEFITS AND ACCIDENTS AT WORK IN BRAZIL IN 2020}

${ }^{1}$ Telma de Cassia dos Santos Nery, Naiara Santos, Eric Kiyoshi Mochizuki Hara, Daniel Nery Cardoso. 'HCFMUSP, Brazil

10.1136/OEM-2021-EPI.210

Introduction On March 11, 2020, the World Health Organization declared the existence of a pandemic by SARS-CoV-2. On May 10, 2021, Brazil had reached the 410,000 mark, becoming the second country in number of deaths from COVID-19 and more than 15 million infected. COVID-19 generates withdrawal from work activities and consequent social security benefits. Knowing the profile of employees and benefits can contribute to a better overview of occupational approaches to COVID-19.

Objective To analyze social security benefits generated by COVID-19 leave in Brazil.

Methodology Descriptive analysis of data from the Observatory of Safety and Health at Work, in the period 2020, referring to social security benefits by COVID-19, with a comparative analysis of the year 2019. All social security gaps were considered. Used ICD - $10=$ U07 and B34. Data analyzed: state of Brazil, occupation, economic activity, notification with 'report of work accident - CAT', age, gender, economic sector.

Results 50 thousands were dismissed from social security benefits in 2020 according to CID U07 and B34. The state of Sao Paulo had the highest frequency with $36 \%$. Men were $68 \%$. The most prevalent economic sector was hospital (15\%) and the occupation was nursing technicians (38\%) The most frequent age group in men was 18-24 years and in women, it was 35 to 39 years.

Conclusion Occupational epidemiology acting in the analysis of secondary, social security data on COVID-19 can contribute to the definition of public policies, expanding health promotion and prevention.

\section{P-139 COMPARATIVE ANALYSIS OF THE FRENCH OCCUPATIONAL EXPOSURE DATABASES COLCHIC AND SCOLA}

${ }^{1}$ Gautier Mater, Jean-Francois Sauve, Jérôme Lavoué. 'Institut national de recherche et de sécurité (INRS), France

\subsection{6/OEM-2021-EPI.211}

Objectives In France, two occupational exposure databases with different goals co-exist. Colchic was built to store measurements from prevention activities since 1987, while Scola contains measurements from compliance monitoring since 2007. We aimed to compare exposure levels between these databases targeting the same population of workers.

Methods Despite their different objectives, both databases share the same structure. We selected personal measurements with a sampling duration $\leq 12$ hours of airborne chemical substances with $\geq 1,000$ results in each database between 2007 and 2015 and combined into a single dataset. We used Tobit models to measure associations between log-transformed concentrations and six predictors (sampling year and duration, global ventilation, number of workers, personal protective equipment (PPE) and region) for each agent. We combined agent-specific models using meta-analytic approaches. We assessed average differences between Colchic and Scola for four prediction scenarios based on sampling year and duration.

Results We selected 239,968 measurements (25\% from Colchic and $75 \%$ from Scola) across fifteen substances (66\% organic solvents, $27 \%$ dusts, and $7 \%$ metals). The most prevalent agents were wood dust $(n=42,193)$, respirable dust $(n=25,299)$ and quartz $(n=23,774)$. Non-detects represented $45 \%$ of all measurements. PPE, sampling year and duration were the main predictors of exposure levels. For 2007, predicted exposure levels in Scola were 2.3 times lower than in Colchic, regardless of sampling duration. This difference decreased in recent years: predicted exposure levels for 2015 were 1.25 times higher in Scola than Colchic for a sampling duration of 30 minutes, and 1.18 times lower in Scola than Colchic for a duration of 240 minutes.

Conclusions Colchic and Scola both represent important sources of information on historical and current occupational exposures in France. Despite a notable early difference in average exposure levels between Colchic and Scola, our results suggest that the contrasts in exposure are getting smaller over time.

\section{P-150 PESTICIDE EXPOSURE OF OPERATORS DURING TREATMENT TASKS IN APPLE GROWING: RESULTS FROM THE CANEPA STUDY IN FRANCE}

${ }^{1}$ Mathilde Bureau, Béatrix Béziat, Geoffroy Duporté, Yannick Lecluse, Elsa Robelot, Lucie De Graaf, Morgane Bresson, Emmanuelle Barron, Valérie Bouchart, Alain Garrigou, MarieHélène Dévier, Hélène Budzinski, Pierre Lebailly, Isabelle Baldi. 'Université de Bordeaux, France

\subsection{6/OEM-2021-EPI.212}

Introduction Although apple trees are heavily sprayed, few studies are available on pesticide exposures of workers in apple orchard. However, these data are crucial for assessing the health impact of such exposures.

Objectives The CANEPA study was performed to measure pesticide exposures during treatment tasks in apple orchard and to identify their determinants.

Methods A non-controlled field study was conducted in apple orchards in four regions of France in 2016-2017. We measured operators' external contamination to captan and dithianon, two fungicides representative of pesticide use in apple growing. Measurements of contamination were performed during mixing/loading, spraying and equipment cleaning tasks, following the OECD guidelines with cotton pads placed onto 11 body areas, cotton gloves or hand rinsing 